
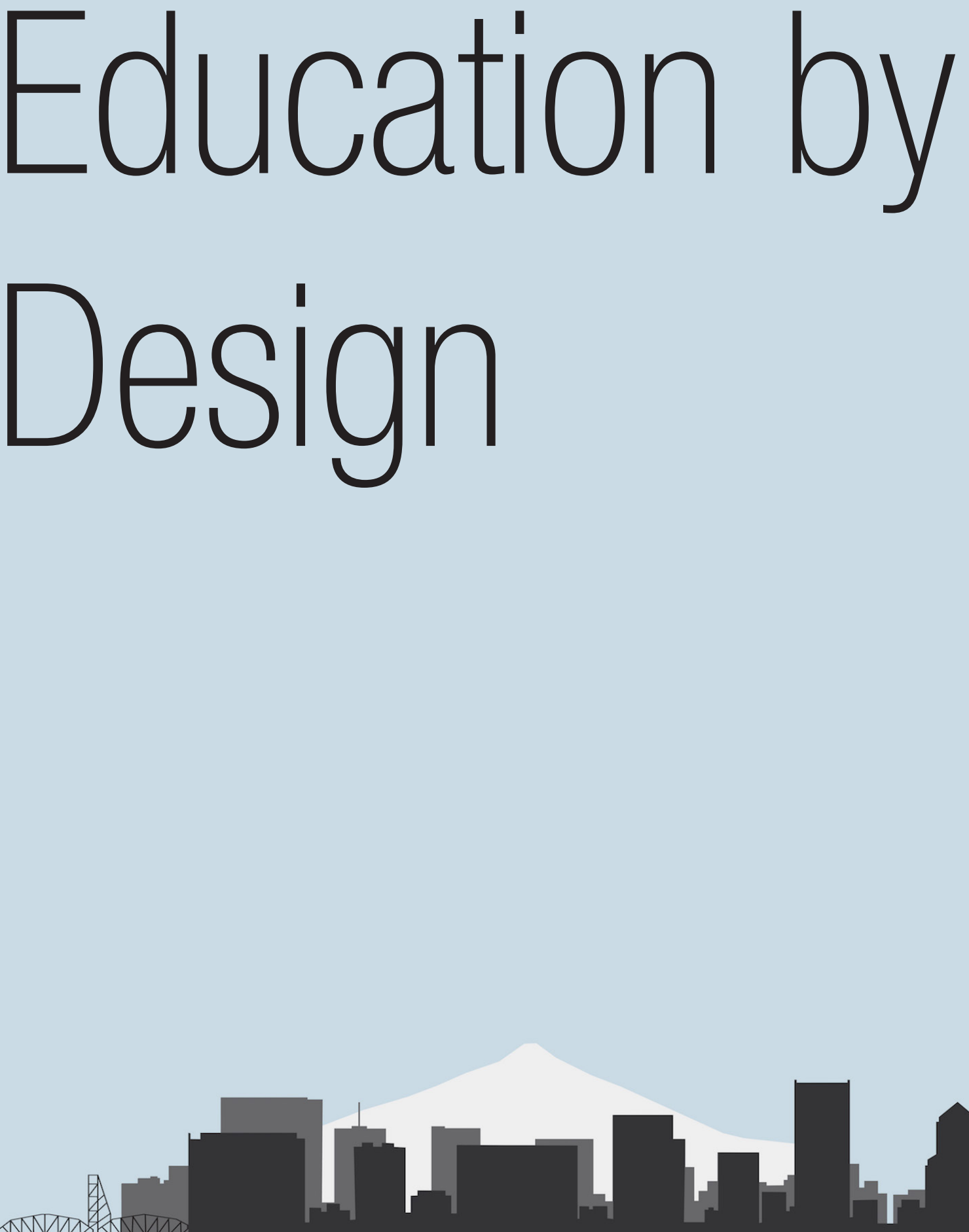

2019 Reynolds Symposium: Education by Design October 18-20, 2019 


\section{Organizing Committee:}

[co-organizers]

Professor Alison Kwok, Ph.D, FAIA, University of Oregon

Emeritus Professor John Reynolds, FAIA, University of Oregon

\section{[Symposium coordinator]}

Isabel Rivera, Ph.D., University of Oregon

Professor Walter Grondzik, P.E., Ball State University

Professor Bruce Haglund, AIA Assoc., University of Idaho

Assistant Professor Emily McGlohn, AIA, Auburn University

Associate Professor Ulrike Passe, lowa State University

Assistant Professor Siobhan Rockcastle, Ph.D., University of Oregon

Sharon Refvem, FAIA, LEED Fellow, Senior Associate and Director, Sustainability Resource Group, Hawley Peterson Snyder 


\title{
Environmental Design: moving towards online teaching that encourages action
}

\author{
Andrea Martínez Arias, Ph.D. \\ Assistant Professor \\ Universidad de Concepción \\ Concepción, Chile \\ amartineza@udec.cl
}

\author{
Pablo La Roche, Ph.D. \\ Professor \\ Cal Poly Pomona University \\ Pomona, California \\ pmlaroche@cpp.edu
}

\begin{abstract}
The internet not only has changed a vast spectrum of the world's operations, but also the ways teaching can deal with information and strategies for learning. While this trend has naturally led to the flexibility of time and location, it is crucial to focus on understanding effective pedagogical strategies with the use of this technology. This paper establishes the thesis that an online setting was effective in teaching both the fundamentals of regenerative studies, while focusing on how undergraduate students learned in this online learning setting. The online coursework and its challenges are discussed along with the structure and methods set to achieve the comprehension of the contents. The urgency for the search of a clear plan and actions to address climate change was the main goal of the class, which was explained in the current political and social context. Consecutively, critical topics of energy, water, shelter, and waste were explored individually, from the main challenges to the design solutions for regeneration. The paper also explains how surveys were a vital tool and an essential instance for feedback. Lessons learned from creating a virtual learning environment that allows for both the grasp of everyone's role in climate change and the generation of action/plans/solutions for regeneration are discussed, aiming to inform colleagues using a teaching tool that is here to stay.
\end{abstract}

\section{INTRODUCTION}

Online education has become an essential platform for learning in higher education, which has been in the process of transition in the last decades (Howell, Williams, and Lindsay 2002). No difference in performance has been found on some fields (Summers, Waigandt, and Whittaker 2005). However, it has been less explorative in the areas of design, due in part to the practical nature that evolves from a masterapprentice, face-to-face contact that defines studio classes. However, online courses allow for new methods of teaching and dynamics between students that are worth exploring in areas that complement the design and provide the fundamentals of sustainability so much needed to be taught to students across all fields of study, including those from design majors.

California State Polytechnic University (CPP) is taking this lead and has incorporated online instruction into its curricula. Within the institution, an increasing number of programs are being offered through the College of Extended University in partnership with ed2go for professional development via certifications. Those courses are web-based learning programs designed by professionals and faculty from each respective field of study. At the same time, the University is increasing the applicability of this technology into platforms for hybrid and fully online courses to undergraduate levels as an alternative to a traditional classroom setting.

This paper describes the experience on transitioning to online-mode from a traditional presence-mode (classroom) course at the Lyle Center for Regenerative Studies. The two main goals of this academic experience were to set the urgency for teaching theoretical concepts, while at the time encouraging real action to address climate change. This paper describes first the structure that was set up to achieve the comprehension of the contents of the course. It follows by describing the activities developed by the students that allowed them to become aware of their role as agents of change. Finally, instances for feedback are explained through their role that allowed detecting any improvement during the development of the new course. The final evaluation done by the students of the course is also described. 


\section{THE COURSE}

The Introduction to Regenerative Studies is a course that is part of the general education curriculum available to undergrad students from all majors in the University and taught at the Lyle Center for Regenerative Studies which is part of the College of Environmental Design at CPP. Within its curricula, the course is aimed at providing students with a joint commitment towards the discovery of workable solutions to complex environmental and cultural concerns. In specific, this course is described as a survey of interactions between physical, biological, and social systems essential for human life, including food, water, energy, shelter, and waste management (CalPoly Pomona Catalog 2019). The main goal of the course is to develop in students a conscious understanding of the relationship between people and their social and physical environments, through an examination of systems that sustain future generations through the regeneration of critical resources and ecosystem processes.

The course contemplated the following learning objectives:

- Gain awareness of environmental challenges at the global, national, regional, and local levels.

- Understand the primary resources and processes that support life: food, water, shelter, energy, and waste management.

- Develop a conscious understanding of the relationship between people and their social and physical environment.

- Acquire a more extensive understanding of the foundations of regenerative practices from theoretical and practical perspectives.

- Examine systems that sustain future generations through the regeneration of critical resources and ecosystems.

- Develop a sense of responsibility for sustainability and promoting sustainable practices through individual and collective action.

A total of 39 students enrolled in the course. Figure 1 illustrates the majors. There are students from many majors and most come from architecture (18\%) and landscape architecture (18\%).
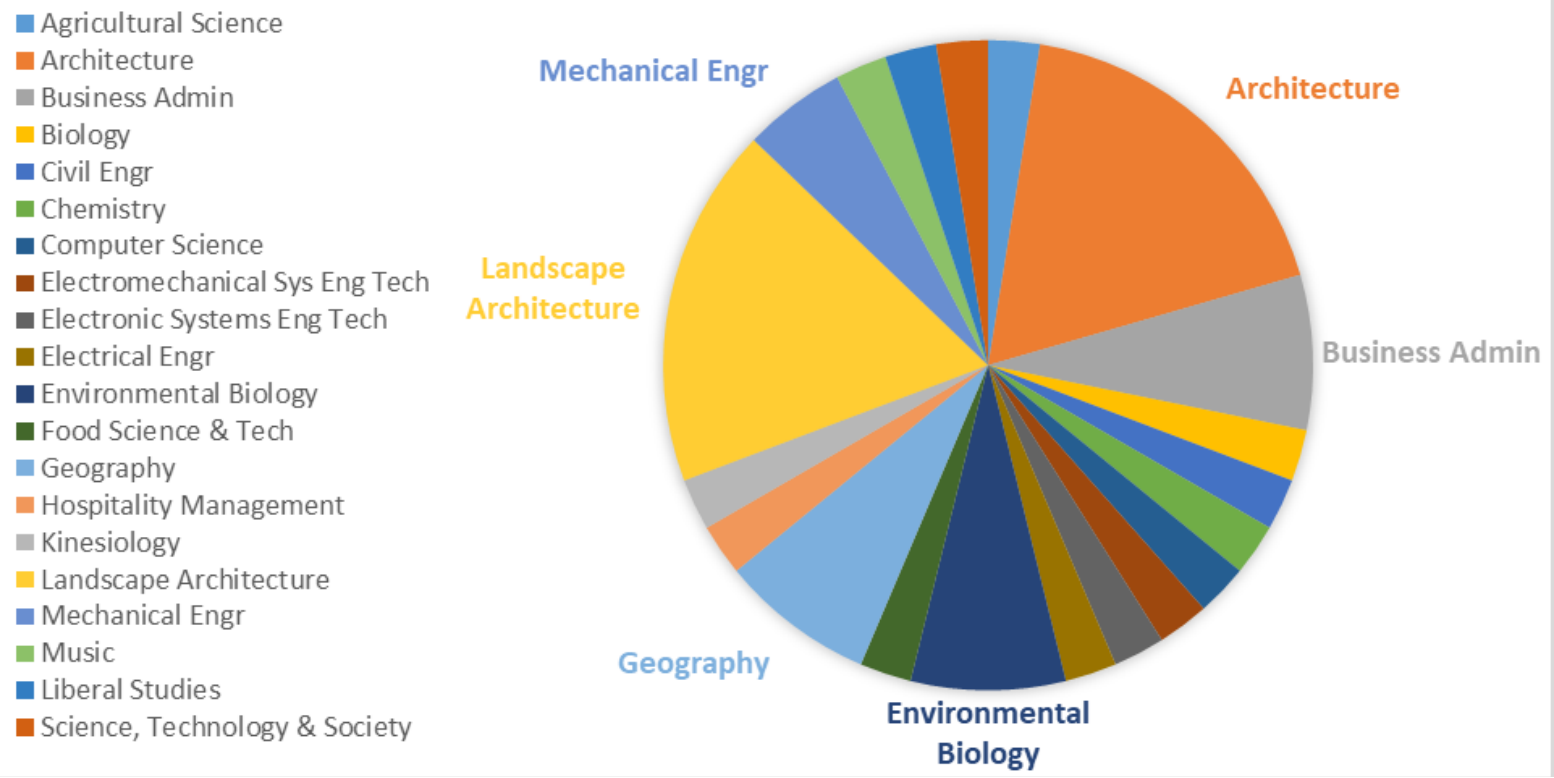

Figure 1. Diagram with students' majors. Labeled those of $5 \%$ and more. 


\section{Course primary approach: From theory to application}

As mentioned, the goal set for the course was to deliver the fundamentals while incubating action. For doing so, the course was structured in three parts: awareness, exploration, and application, as illustrated in Figure 2. The intent was moving from a conscious understanding of climate change, the anthropogenic causes, and the importance of regenerative studies to implement practical solutions at the end of the course.

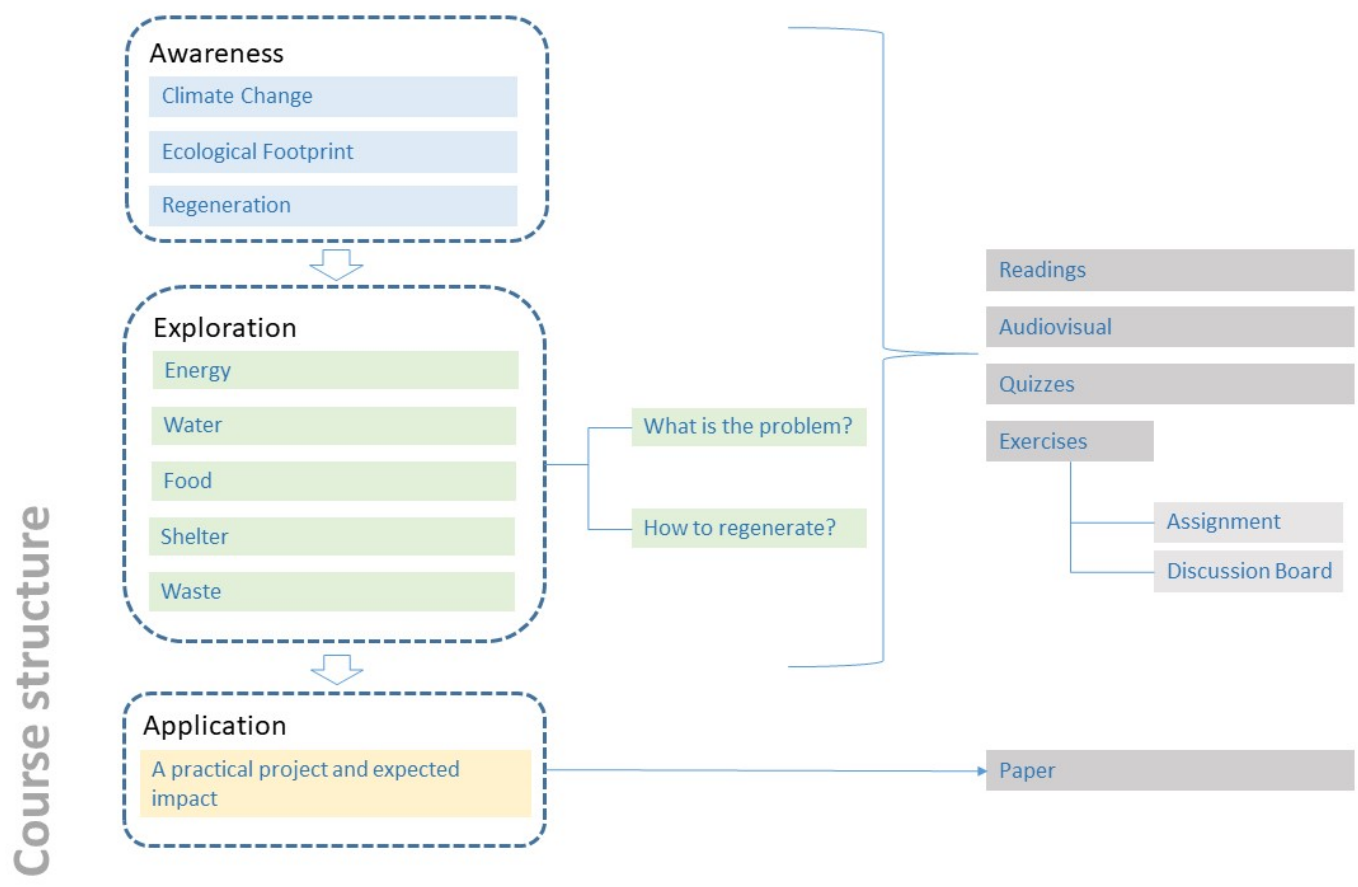

Figure 2. Main structure of the course

The course was developed for 15 weeks of instruction during the Fall semester. Various online teaching activities were useful for recreating classroom activities. An online module platform (Blackboard) was facilitated and supported by the institution and the Information Technology team at Cal Poly.

- Lectures. Pre-recorded lectures of about $15 \mathrm{~min}$ were developed through video editing software (Camtasia) and delivered weekly in a video format (.mp4).

- Readings: Mandatory and recommended readings to complement the topics covered in the lecture.

- Audiovisual material: Short audiovisuals (with a relevant number of TED talks) were organized according to the relevance of the week's topic.

- Short quizzes: A weekly 3-question quiz was required of the students. This instance was graded and asked to be completed at the end of the lectures to allow a full understanding of the covered concepts.

- Assignments: Short assignments consisted of calculations (i.e., footprints) and essays.

- Discussion Forum: A discussion board available on the platform was used for discussion among students about topics approached in lectures. It provided an opportunity to engage with other students and agree or disagree with each other's ideas and opinions.

- Final project: the full understanding of the concepts covered during the semester were applied to a project that was proposed by the students to demonstrate their regenerative thinking approach. 
This course was intended to have a balanced combination of theoretical content linked to practical exercises. It also found useful information and feedback about the background and acknowledgment of the students in the topics covered.

\section{Awareness}

The stage defined as "awareness" was intended to make students reflect on their knowledge about climate change and their role in it. For this, the primary definition of concepts was delivered to provide a basic understanding of climate change and global warming, ecological footprint, and regeneration.

It was initiated with a diagnostic that was inspired in an article by Maree Brown titled "The Green Generation" (Maree Brown 2007), which documented the perceptions and opinions of young people as crucial protagonists on the coming decades in view of climate change. Maree's exercise was intended not only to knowing what they understand, but what they are doing about it. Sharing the same objectives and similarly to Maree's use, a diagnostic was applied to the students as the first activity to the online course. This diagnostic exercise consisted of five open-ended questions:

- Please provide your definition of Global Warming.

- How did you learn about global warming?

- Do you think you will see the effects of global warming in your lifetime?

- Is your generation doing enough?

- Are you engaged in some actions to address our planet's environmental, social, or economic pressures that call for regenerative actions? If so, which?

A total of 32 diagnostic surveys were submitted, answering all five questions. It resulted in accurate and well-developed descriptions, including half of the answers explicitly referring to human activities as one of the leading causes. Regarding how they learned about Global Warming, the majority of responses describedthe media as one of the primary sources. Despite the important role that media has in this generation, it is vital to notice that classroom settings have been a significant scenario in learning about global warming (Figure 3). Although covered in the curricula of high-school and higher education, it was noticed that only 3 answers explicitly indicated that they learned about global warming in primary school.

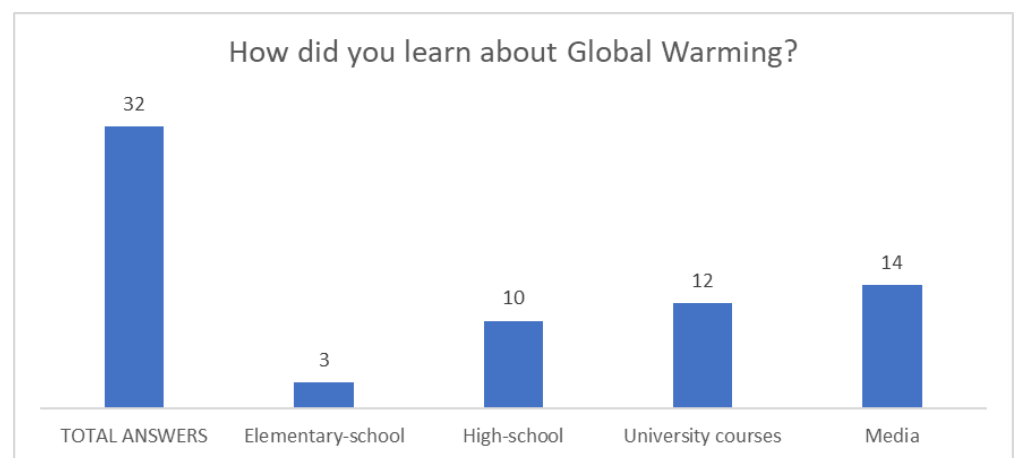

Figure 3. Number of responses referring to different sources of introduction to Global Warming

Although expected, all students indicated they would see the effects of global warming in their lives, reflecting their awareness not only of the phenomenon but also about the many manifestations. In fact, $94 \%$ of them recognized that they think they are experiencing the effects of global warming already. However, when they were asked if they are doing enough to stop global warming, 84\% of the answers were definite to indicate that their generation is not doing enough. Despite the fact that the majority recognized there is still much to do, $19 \%$ of the students reported that they are doing what is possible for them. They also realized that it takes not only them, but other generations and big industry to take real action. Yet, even though they felt that they are not doing enough, the students taking this course seem to be already taking some concrete steps to address our planet's environmental, social or economic pressures that call for regenerative measures. As illustrated in Figure 4, a portion of the students recognized not being part of a concrete action (8/32), while slightly over half of them indicated they are involved in some 
activity. Among those involved, they described actions at a personal level (12/32), whereas a smaller portion reported involvement through some organizations and volunteering (6/32).

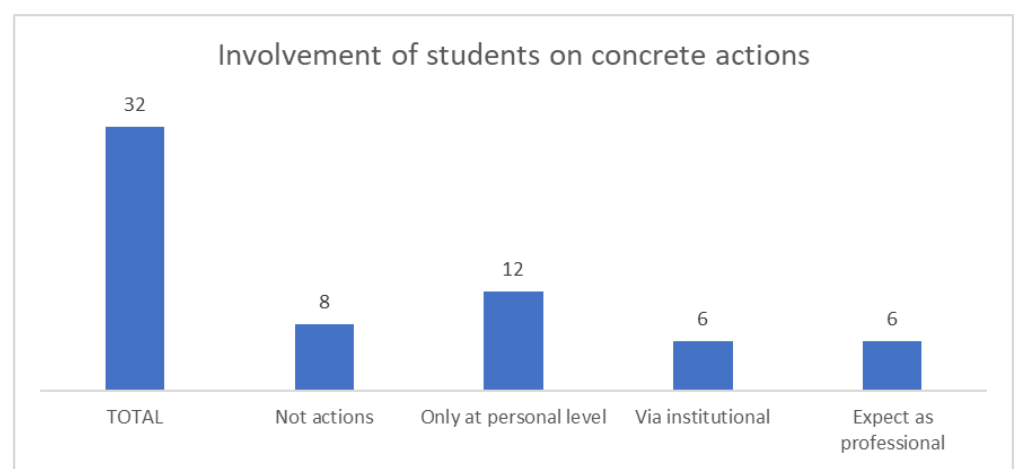

Figure 4. Number of responses referring to engagement in actions to address our planet's environmental, social or economic pressures that call for regenerative actions

While many of them recognize themselves as agents of change, some of them visualize their commitment in the near future as professionals. Students from architecture and landscape majors visualize themselves as agents, developing an environmentally conscious design, changing the approach to building, being part of the movement towards a cleaner architecture, and educating clients. They also reported actions such as drought-tolerant planting, volunteering at institutions (aquariums, wetlands), educating visitors about climate change, and restoring natural areas.

\section{Exploration}

The stage defined as "exploration" was intended as a transition to an action. It was set as a series of paired sessions by the topics included in the course: energy, water, food, shelter, and waste. Of the two sessions, the first was focused on the problem, while the second session focused on exploring examples of successful strategies and concrete solutions. Those sessions were complemented by audiovisual material, while the second session generally contemplated activities where the students could work on personal footprints to be discussed on the forum. Table 1 summarizes how those sessions were supported by different formats, in relation to the areas explored by each activity.

Table 1. Assignments and Topics on exploration phase

\begin{tabular}{|l|l|l|}
\hline Topic & $\begin{array}{l}\text { Assignment: } \\
\text { Brief TedTalk + Documentary }\end{array}$ & $\begin{array}{l}\text { Discussion Forum } \\
\text { Calculating personal footprints }\end{array}$ \\
\hline Energy & Energy and global warming & Ecological footprint using a web calculator \\
\hline Water & Water crisis & Water footprint using web calculator \\
\hline Food & Food industry & Food footprint using a web calculator \\
\hline Shelter & Homelessness and net-zero housing & Costs of living, estimates \\
\hline Waste & Waste, plastic pollution & Waste footprint \\
\hline
\end{tabular}

Those activities were considered successful because of the high submission rate within the deadlines. As mentioned before, students expressed likeability of audiovisual formats. Similarly, interactive websites for calculating footprints were well received because of their use on realizing the impacts of their actions on the broader context. Footprints for ecological, food, water were included within the exercises. As an example, figure 5 compiles the results of the ecological footprints activity, on which students calculated how many Earth would be necessary based on their consumption pattern. 


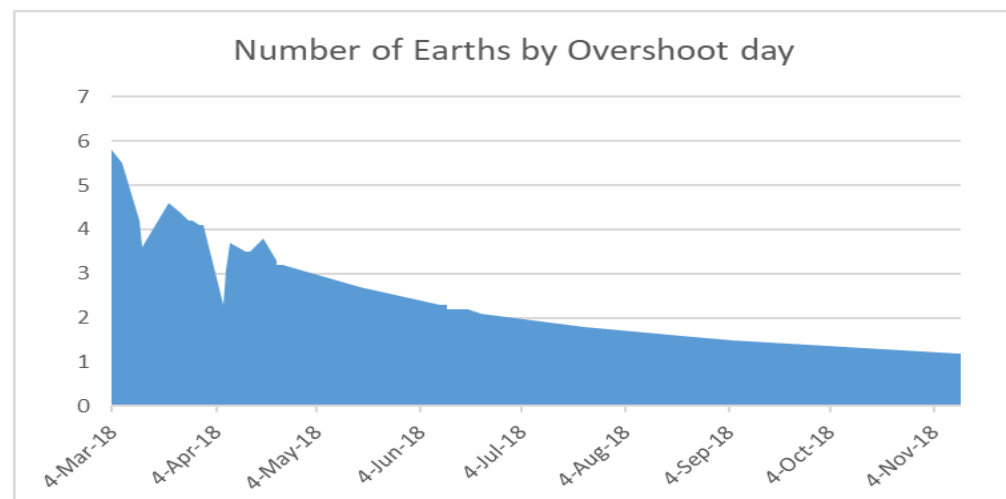

Figure 5. Ecological footprints explored through the discussion forum

\section{Application}

The stage defined as "application" encouraged the students to develop a plan or report a concrete action that could be achieved in a short period of time. Those projects were reported in research paper format. As shown in Figure 6, students' proposals ranged from small activities such as recycling to bigger plans such as education plans for women, or the development of community learning sessions about climate change.

\begin{tabular}{|c|c|c|}
\hline $\begin{array}{l}\text { Public Transportation in the City of Los Angeles } \\
\text { Eliminating the Dryer } \\
\text { An Assessment on the Impacts of Media Surroun } \\
\text { Climate Change Education and Calls for Action } \\
\text { Benefits of biomass and plants } \\
\text { Ecofeminism in Los Angeles } \\
\text { Air drying clothing in the sun } \\
\text { Reduce waste } \\
\text { Composting for Regeneration } \\
\text { Community involved on climate change action ar } \\
\text { Food Choices Survey } \\
\text { Regenerative Thinking Approach in Practice } \\
\text { Indoor composting using Bokashi } \\
\text { Student Run Café } \\
\text { afforestation and slowing the } \\
\text { rate of deforestation } \\
\text { Educating the Young Women of Today } \\
\text { Research for alternative } \\
\text { energies to power our transportation. } \\
\text { Household environmentally friendly actions } \\
\text { Driving more efficiently by reducing speed } \\
\text { The New Age Greenhouse With Fish } \\
\text { Reusable Produce Bags } \\
\text { Composting to A Cleaner Living } \\
\text { Moving from car to an Electric scooter } \\
\text { Campaign solar energy } \\
\text { Control of textile waste } \\
\text { Recycling paper }\end{array}$ & 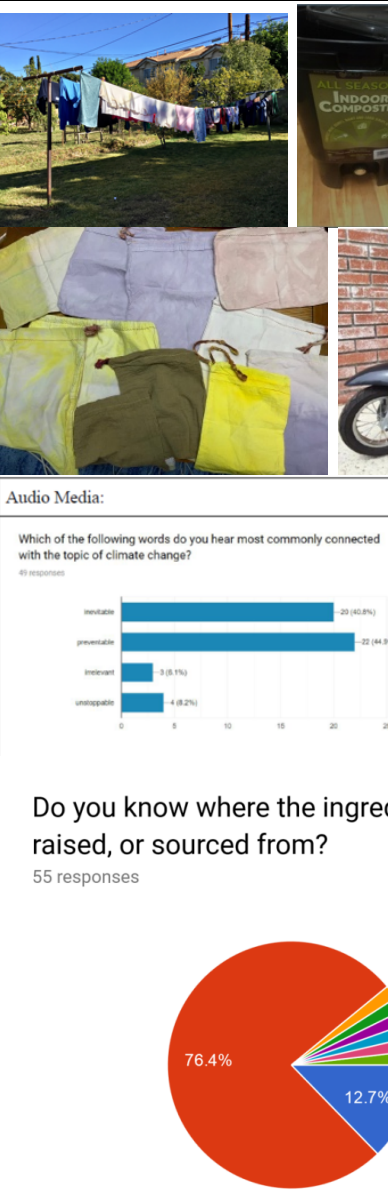 & $\begin{array}{l}\text { Its in this item or meal were grown, } \\
\text { ches } \\
\text { change? } \\
\text { No the fllowing words do you think best conveys climate "local " no farm name means } \\
\text { "somewhere in California" lol } \\
\text { Sometimes } \\
\text { Most of the time } \\
\text { Sometimes it's labeled where it's } \\
\text { from. } \\
\text { Sometimes, if there is a label sta... } \\
\text { Usually where from...also organic... }\end{array}$ \\
\hline
\end{tabular}

Figure 6. Summary of some of the topics of final projects 


\section{THE PROCESS OF FEEDBACK}

\section{Students' feedback}

Halfway through the semester, the students were asked to fill a short survey for providing feedback about the development of the course. The survey consisted of three open-ended questions. The first was to ask what the students liked about the course. A second question asked what they disliked. A third question requested feedback on any suggestion or idea on how to improve the course. A total of 23 surveys were answered, from which exciting and handy ideas arose that helped to improve the second part of the course.

What students liked: All of the students (23/23) responded to this question, manifesting they were glad about different aspects and activities included in the course. Those aspects refer to the format of the course, content, and specific exercises. Regarding the structure of the course, the students highlighted the proposed format (21/23), indicating that they liked the variety of sources and mix of activities. In fact, they valued the brevity of the material, such as lectures, discussion boards, quizzes, and audiovisual. The length of activities and accessibility was noted on lectures, indicating that those went to the point and were easily accessible from their many electronic devices. Audiovisuals (videos) were gladly received and considered more attractive than readings. Also, students explicitly recognized that one of the significant missing components in an online class is the human interaction in a classroom; however, they indicated that discussion boards were a reasonable substitute, which was motivated by the need to reply to classmates' posts. In terms of dynamics, students reported enjoying the consistency of the class towards building a routine, which allowed them quickly to keep track of what assignment was due (either essay or Discussion Board post because of the alternating of the two), and it was not monotonous. Finally, quizzes were found to be useful as they focused on the topic of the session, and they were also brief and gauged their understanding of the material specific to the session.

Regarding the topic and the material of the class, students manifested likeability of the content (19/23), finding the covered material not only inspiring, but also precise and concise for easy comprehension. The content was described as attractive, fun, balanced, and credible. They valued the delivery of the material in brief pieces of audiovisual format by leading experts on the topics. Figure 5 illustrates the different activities. As mentioned, short audiovisual formats such as TED Talks, were quite popular (15/19). Also, discussion boards were considered a useful resource for the online setting. Regarding that, students indicated that they found it an excellent way to interact with the other students in the virtual environment.

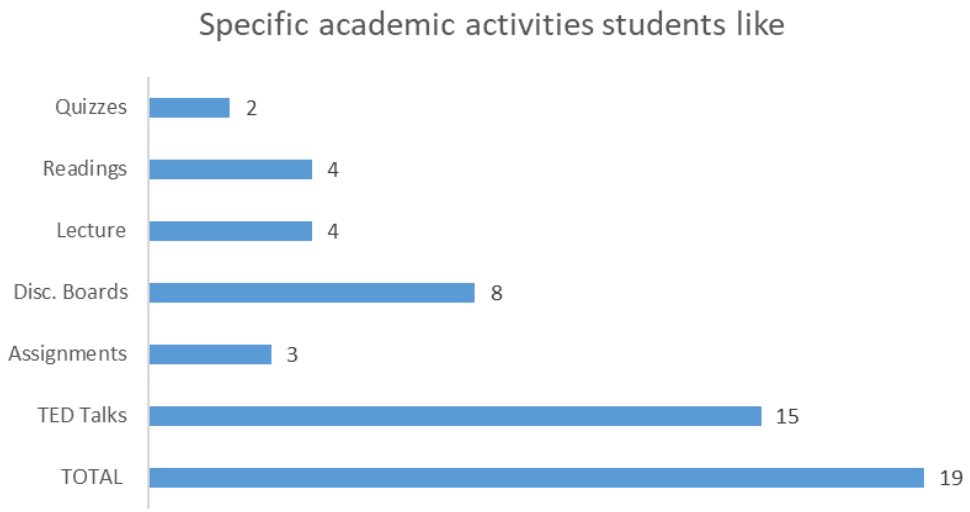

Figure 5. Some of the specific aspects more likable by students

What they disliked: Almost all students (21/23) responded to this question. Figure 6 illustrates some of the aspects students suggested for review. A group of students (9/21) explicitly manifested they liked the course as it was set, and no significant issues bothered them. Among those students providing feedback to this question, they mentioned that some readings were considered too hard for an introductory class. 
Another problem for the students were the deadlines. Though Fridays were set by the instructor with the intent of freeing the students from this class during weekends, a group of students (5/19) indicated that their week was too busy for that setting. A few students (2/19) mentioned that the course was too timeconsuming for a 100-level class, while only one student suggested considering a different organization of the material within the online platform (organized by week instead of by activity).

Specific academic activities students dislike

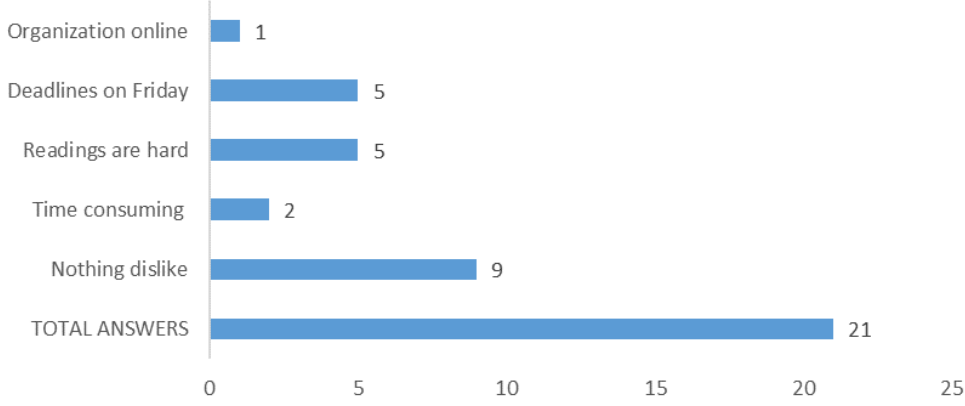

Figure 6. Some of the specific aspects students dislike

What they suggested: Almost all students (22/23) responded to this question. A significant portion replied not having primary suggestions; however, among those providing them, they included the need for interaction with other students, site visits, volunteering, and hands-on activities. Among those, group presentations were mentioned as part of potential projects. They also suggested interaction with other people such as their family, friends, or the public about the topics covered in the course, in order to analyze the level of awareness of the changes occurring in their community.

\section{Adoption of feedback}

Based on the input from the students, it was good to hear that the class was, useful and well received to students. Some adjustments were possible to the second half of the course; yet, others not likely due to the existing setting. Among those easy to apply, were those concerning deadlines and readings. Deadlines were quickly modified (from Fridays to Sundays), while special care was put into the selection of texts in order to restrict papers that were too scientific or technical.

While some changes were incorporated into the course, such as a site visit to the Lyle Center for Regenerative Studies (which was set as an optional activity for students), other changes were challenging to incorporate into the course, such as in-person interactions. However, some degree of personal meetings or activities would be recommended for future versions of the course. Consequently, adjustments like this would take this asynchronous mode to synchronous mode or even a possibility of a hybrid mode. Other suggested activities, such as volunteering, or some other hands-on activities could also be considered and highly recommended. Especially, if set as complementary activities, those alternatives would allow students the right to choose to take them on based on their flexibility and possibilities.

\section{Final evaluation of the course}

At the end of the semester, an academic evaluation is carried by the University on all their courses. For this course, a total of 22 student responses were submitted. The positive assessment of the course is illustrated in the matrix of 10 points, shown in Figure 7. It was gratifying to see that not only the structure for the course, but the content and the activities were well rated by all students. 

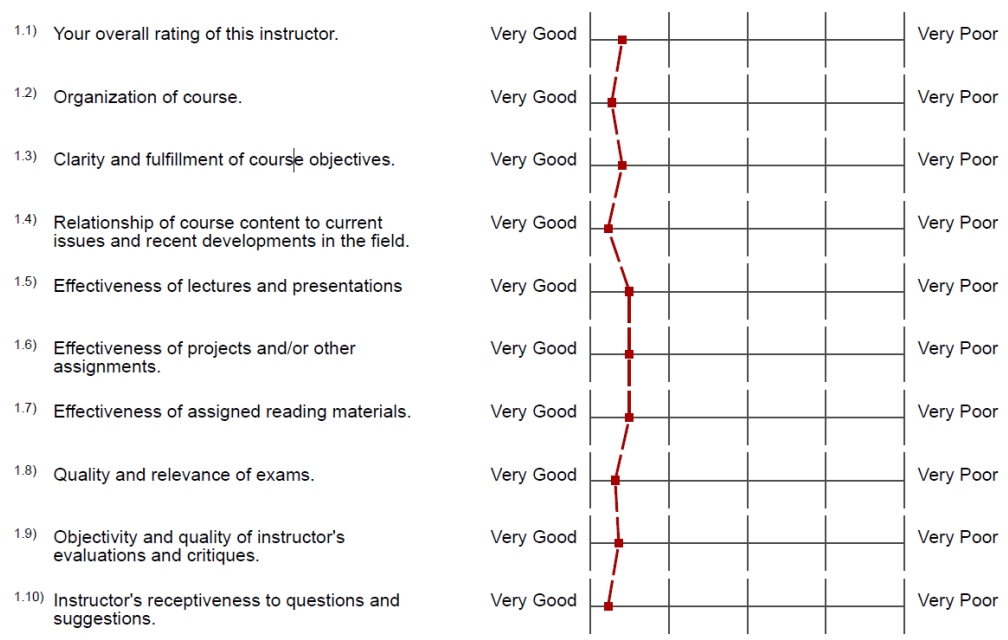

Figure 7. Students evaluation of the online course (source: CPP)

\section{CONCLUSION}

This paper describes the experience of implementing an online version of a traditionally classroom-mode course about regenerative studies. The design of the course, methods, and challenges of this implementation were discussed. While the methods used in the class were proven to be effective in achieving the comprehension of the contents, a number of lessons were learned during its development. Surveys were proven to be a vital tool for evaluation of the students' knowledge and as an instance for feedback. As a diagnostic exercise, it allowed for a better understanding of the topic by all the students, from all majors. The development of the course confirmed the important role of media for this generation of students, used here as a platform for learning. As a tool for feedback, surveys were key for validating the effectiveness of the primary sources and format being used. But most importantly, it allowed identifying those areas of improvement and allowing for the implementation of some of them during the second half of the semester. It was interesting to observe students suggesting more interaction, which could have been quite counterintuitive to the motivations for taking an online course. Despite the fact that a virtual environment allows for a totally free and individual experience, a desire for teamwork, classroom discussions, and collective site visits were still present. Lessons learned from creating a virtual learning environment allowed for both the grasp of everyone's role in climate change and for thinking concretely about achievable actions/plans/solutions. It is hoped that this experience could inform colleagues who are not only using online settings, but also those who are using pedagogical tools responding to the demands of a new generation of students.

\section{ACKNOWLEDGMENTS}

The authors are thankful to the students taking this course and for the support of Cal Poly Pomona in the launch of the course, reflected in the supporting team at the College of Environmental Design, the Lyle Center for Regenerative Studies, and the IT department. Special thanks to Melisa Olivieri. At the time of publication, this paper is partially supported by the PAI 77180057 project.

\section{REFERENCES}

CalPoly Pomona. 2019. Lyle Center for Regenerative Studies Courses 2019 [cited 19/06/2019 2019]. Available from https://env.cpp.edu/rs/course-catalog.

Howell, Scott L., Peter B. Williams, and Nathan K. Lindsay. 2002. "Thirty-two Trends Affecting Distance Education: An Informed Foundation for Strategic Planning." Online Journal of Distance Learning Administration no. 5 (1).

Maree Brown, Adrienne. 2007. "The Green Generation." In The Global Warming Reader, edited by Bill McKibben, 259-267. 
Summers, Jessica J. , Alexander Waigandt, and and Tiffany A. Whittaker. 2005. "A Comparison of Student Achievement and Satisfaction in an Online Versus a Traditional Face-to-Face Statistics Class." Innovative Higher Education, no. 29 (3). 